\title{
Aerosol dynamics within and above forest in relation to turbulent transport and dry deposition
}

\author{
Üllar Rannik ${ }^{1}$, Luxi Zhou ${ }^{1}$, Putian Zhou ${ }^{1}$, Rosa Gierens ${ }^{1}$, Ivan Mammarella ${ }^{1}$, Andrey Sogachev ${ }^{2}$, and Michael Boy ${ }^{1}$ \\ ${ }^{1}$ Department of Physics, University of Helsinki, P.O. Box 48, 00014 Helsinki, Finland \\ ${ }^{2}$ Department of Wind Energy, Technical University of Denmark, 4000 Roskilde, Denmark \\ Correspondence to: Üllar Rannik (ullar.rannik@ heuristica.ee)
}

Received: 7 June 2015 - Published in Atmos. Chem. Phys. Discuss.: 16 July 2015

Revised: 2 January 2016 - Accepted: 19 February 2016 - Published: 9 March 2016

\begin{abstract}
A 1-D atmospheric boundary layer (ABL) model coupled with a detailed atmospheric chemistry and aerosol dynamical model, the model SOSAA, was used to predict the ABL and detailed aerosol population (characterized by the number size distribution) time evolution. The model was applied over a period of 10 days in May 2013 to a pine forest site in southern Finland. The period was characterized by frequent new particle formation events and simultaneous intensive aerosol transformation. The aim of the study was to analyze and quantify the role of aerosol and ABL dynamics in the vertical transport of aerosols. It was of particular interest to what extent the fluxes above the canopy deviate from the particle dry deposition on the canopy foliage due to the above-mentioned processes. The model simulations revealed that the particle concentration change due to aerosol dynamics frequently exceeded the effect of particle deposition by even an order of magnitude or more. The impact was, however, strongly dependent on particle size and time. In spite of the fact that the timescale of turbulent transfer inside the canopy is much smaller than the timescales of aerosol dynamics and dry deposition, leading us to assume well-mixed properties of air, the fluxes at the canopy top frequently deviated from deposition inside the forest. This was due to transformation of aerosol concentration throughout the ABL and resulting complicated pattern of vertical transport. Therefore we argue that the comparison of timescales of aerosol dynamics and deposition defined for the processes below the flux measurement level do not unambiguously describe the importance of aerosol dynamics for vertical transport above the canopy. We conclude that under dynamical conditions reported in the current study the micrometeorological particle flux measurements can significantly deviate from the dry de-
\end{abstract}

position into the canopy. The deviation can be systematic for certain size ranges so that the time-averaged particle fluxes can be also biased with respect to deposition sink.

\section{Introduction}

Turbulent fluxes of scalars are commonly measured by the eddy covariance (EC) technique above forests. From flux measurements the exchange of scalars between the ecosystem and the atmosphere is inferred by making simplifying assumptions, mainly horizontally homogeneous and stationary conditions, considering usually transport of passive scalars. From aerosol particle flux measurements deposition to ecosystem is inferred by neglecting all additional terms including the storage term. However, there are several mechanisms affecting the particle concentration, namely new particle formation, coagulation and source or sink terms for a particular size resulting from condensational growth. These processes, which we refer to as the aerosol dynamical processes throughout this study, govern the particle size distribution evolution. The significance of aerosol dynamical terms in comparison to dry deposition has been evaluated by comparing the respective timescales. The timescale for dry deposition for measurement level $z$ has been estimated according to $\tau_{\mathrm{dep}}(z)=\frac{z}{V_{\mathrm{d}}}$, where $V_{\mathrm{d}}=-\frac{F(z)}{C(z)}$ denotes the bulk deposition velocity defined as the ratio of the total flux divided by the concentration at the same level (Pryor and Binkowski, 2004; Pryor et al., 2013). Such a definition of the timescale of dry deposition implies that frequently the aerosol dynamical terms have similar timescales to dry deposition and therefore affect the conservation of aerosol particle concentration 
during the transport pathway between the EC measurement level and the collecting surfaces. Depending on the particle size and the prevailing conditions, i.e., the nucleation rate, the availability of condensing vapors determining the condensational growth and the shape of the particle size spectrum, the aerosol dynamical terms can vary significantly. The timescale of aerosol dynamical processes varies typically between $10^{3}$ and $10^{5} \mathrm{~s}$ (Pryor and Binkowski, 2004; Pryor et al., 2013), i.e., being on the hourly timescale and more. This is a sufficient time to allow well-mixed conditions to establish within the unstable daytime atmospheric boundary layer $(\mathrm{ABL})$, where the mixing timescale is estimated to be around $10 \mathrm{~min}$ (e.g., Stull, 1988). Under near-neutral and stable conditions such efficient mixing throughout atmospheric column cannot be assumed. Instead the characteristic timescales of turbulent transfer within and above forests have been estimated by different approaches (e.g., Zelger et al., 1997; Rinne et al., 2000, 2012; Rannik et al., 2009b). Such timescales of turbulent transfer depend on the observation conditions but typically remain on the order from a few tens of seconds to a few hundreds of seconds. In spite of different definitions used and large variation range of the timescales characterizing the scalar transport between the observation level and the collecting surfaces within forest, the turbulent transfer can be expected to occur much faster than the aerosol dynamical processes.

The aerosol particle dry deposition is strongly size dependent as different mechanisms operate at different particle sizes. The timescale of dry deposition depends on particle size and exhibits its maximum at around $100 \mathrm{~nm}$. For small particles with a few nanometers in diameter this dry deposition timescale can be orders of magnitudes smaller due to efficient removal mechanism by Brownian diffusion. At particle sizes larger than $100 \mathrm{~nm}$ the particle collection is again enhanced due to interception and inertial impaction mechanisms (Petroff et al., 2008) and the respective timescale of dry deposition is smaller. In general, the dry deposition timescale has been frequently estimated to be in the same order of magnitude as the timescale for aerosol dynamics, leading to a conclusion that flux divergence may occur during transport due to aerosol dynamics (Pryor and Binkowski, 2004; Pryor et al., 2013).

The timescales of turbulent transfer and the timescale of dry deposition embed essentially different definitions and can lead also to different conclusions about the significance of aerosol dynamical terms during the transport between the underlying surfaces and the measurement level. The timescale of turbulent transfer is the characteristic time of the transfer within turbulent air layer. Dry deposition includes in addition the transport pathway within the laminar air layer surrounding the collecting surfaces. In the resistances framework (e.g., Monteith and Unsworth, 1990), the dry deposition includes the aerodynamic (corresponding to turbulent transport) as well as the leaf laminar sublayer resistances and under most conditions the dry deposition is lim- ited by the laminar boundary layer transfer (e.g., Petroff and Zhang, 2010). Therefore comparison of the timescales of turbulent transport and dry deposition with that of aerosol dynamics leads us to the assumptions that (i) turbulent transport within and above forest is relatively fast and no significant transformation of aerosol population occurs within the respective timescale and (ii) depending on particle size the removal of aerosols via dry deposition occurs at the comparable timescale with aerosol dynamics and therefore the aerosol population can be modified during the removal process. Such modification occurs on hourly timescales and therefore is expected to occur throughout the ABL, where aerosol dynamical processes can depend strongly on height within the ABL via vertical profiles of condensing vapors.

The purpose of this study is to analyze the magnitude of different terms in the particle number conservation equation and to evaluate the timescales of particle turbulent transfer, aerosol dynamical processes and dry deposition over a wide range of particle sizes. Further, we evaluate the effect of these terms on inferring particle deposition velocities from flux measurements by micrometeorological techniques, in particular the influence on estimation of functional dependencies as well as systematic biasing effects. The study relies on the simulations by the model to Simulate the concentration of Organic vapors, Sulphuric Acid and Aerosols (SOSAA) and the measurements were used only to initialize the model (see Sect. 2.2 and Appendix B) or for evaluation of model outputs in terms of predicted particle size distributions and meteorological variables such as heat fluxes above canopy (see Sect. 3 below). Non-stationary conditions will be considered by simulating detailed ABL and aerosol dynamics inside and above the forest canopy during a period of 10 days, which includes highly dynamical conditions with new particle formation.

\section{Materials and methods}

The model was set up for a pine forest site in southern Finland and initialized with available measurements performed at the SMEAR II station. For description of the site and initialization of the model see Appendices A and B, respectively. The analysis relies on evaluation of the significance of different terms of the particle conservation equation.

\subsection{Conservation equation for aerosol size distribution}

In horizontally homogeneous conditions, when neglecting molecular diffusivity and applying the first-order closure to turbulent flux,

$\overline{w^{\prime} n^{\prime}}=-D_{\mathrm{t}} \frac{\partial \bar{n}}{\partial z}$,

the conservation equation for time-averaged particle number density $\bar{n}=\frac{\mathrm{d} \bar{N}}{\operatorname{dog}_{10} D_{\mathrm{p}}}$ inside the canopy can be written as 
$\frac{\partial \bar{n}}{\partial t}+\frac{\partial}{\partial z}\left(-D_{\mathrm{t}}(z) \frac{\partial \bar{n}}{\partial z}-w_{\mathrm{s}} \bar{n}\right)=-a(z) v_{\mathrm{c}} \bar{n}+S_{\mathrm{ad}}$,

where $\bar{N}$ is the average particle number concentration, $D_{\mathrm{p}}$ the particle diameter, $D_{\mathrm{t}}$ the particle turbulent diffusivity, $w_{\mathrm{s}}$ the settling velocity, $v_{\mathrm{c}}$ the particle collection velocity by vegetation and $a$ the all-sided leaf area density. The source/sink term $S_{\text {ad }}$ incorporates all aerosol dynamical terms, consisting of nucleation $S_{\text {nucl }}$, condensational growth $S_{\text {cond }}$ and coagulation $S_{\text {coag }}$ terms. If the condensational growth rate is considered as $I_{\text {cond }}\left(\log _{10} D_{\mathrm{p}}\right)=\frac{\mathrm{d}_{\log } D_{\mathrm{p}}}{\mathrm{d} t}$, then the respective source/sink term in Eq. (2) is expressed as $S_{\text {cond }}=$ $\left[\frac{\partial \bar{n}}{\partial t}\right]_{\text {cond }}=-\frac{\partial\left(I_{\text {cond }} \bar{n}\right)}{\partial \log _{10} D_{\mathrm{p}}}$. For particle size range up to a few micrometers $D_{\mathrm{t}}$ can be assumed to be equal to the eddy viscosity of the flow. The settling velocity $w_{\mathrm{s}}$ is given as

$w_{\mathrm{s}}=\frac{C_{\mathrm{c}} g \rho_{\mathrm{p}} D_{\mathrm{p}}^{2}}{18 \eta}$

where $g$ is the acceleration due to the gravity, $\eta$ the dynamic viscosity of air, $\rho_{\mathrm{p}}$ the particle density and $C_{\mathrm{c}}$ the Cunningham slip correction factor (e.g., Hinds, 1982).

For the comparison of the significance of different terms of the conservation equation, the Eq. (2) was re-written so that the sum of all terms equaled 0 , and the transport due to settling was merged with the particle collection by vegetation as

$$
\begin{aligned}
& {\left[-\frac{\partial \bar{n}}{\partial t}\right]+\left[\frac{\partial}{\partial z}\left(D_{\mathrm{t}}(z) \frac{\partial \bar{n}}{\partial z}\right)\right] } \\
+ & {\left[-a(z) v_{\mathrm{c}} \bar{n}+\frac{\partial}{\partial z}\left(w_{\mathrm{s}} \bar{n}\right)\right]+\left[S_{\mathrm{ad}}\right]=0, }
\end{aligned}
$$

where the terms were called the storage, (vertical) transport, particle deposition and aerosol dynamical terms. Further, integration of Eq. (4) from the forest floor surface up to the canopy top $h$ was used to define the change velocities in analogy to deposition velocity. The change velocity due to particle deposition was defined as

$V_{\mathrm{dep}}=\frac{1}{\bar{n}(h)} \int_{0}^{h}\left[-a(z) v_{\mathrm{c}} \bar{n}+\frac{\partial}{\partial z}\left(w_{\mathrm{s}} \bar{n}\right)\right] \mathrm{d} z$

and the change velocity due to aerosol dynamics as

$$
V_{\mathrm{ad}}=\frac{1}{\bar{n}(h)} \int_{0}^{h} S_{\mathrm{ad}} \mathrm{d} z .
$$

In particular, for the transport term the respective change velocity was defined as

$$
\begin{aligned}
V_{\text {transp }} & =\frac{1}{\bar{n}(h)} \int_{0}^{h} \frac{\partial}{\partial z}\left(-\overline{w^{\prime} n^{\prime}}\right) \mathrm{d} z \\
& =-\frac{\overline{w^{\prime} n^{\prime}}(h)-\overline{w^{\prime} n^{\prime}}(0)}{\bar{n}(h)} .
\end{aligned}
$$

Note that in the modeling approach the vertical flux at the canopy top was obtained from the gradient diffusion approximation (Eq. 1) and the flux at the surface was defined by the ground deposition parameterization, which was applied as the sink term in the lowest model layer. Therefore in our model calculations $\overline{w^{\prime} n^{\prime}}(0)=0$ and the transport velocity equaled to the exchange velocity defined at the canopy top by

$V_{\mathrm{e}}=-\frac{F(h)}{\bar{n}(h)}$.

The timescales of the processes affecting the particle concentration inside the canopy were defined by

$\tau=\frac{h}{V}$,

with the change velocities $V_{\mathrm{dep}}, V_{\mathrm{ad}}$ and $V_{\mathrm{e}}$ defining the timescales for deposition $\tau_{\text {dep }}$, aerosol dynamics $\tau_{\text {ad }}$ and exchange $\tau_{\mathrm{e}}$, respectively. These timescales were calculated based on the numerical modeling results by SOSAA.

\subsection{Simulation of aerosol transport and dynamics by model SOSAA}

The model SOSAA is a 1.5-order RANS (Reynolds-averaged Navier-Stokes) model SCADIS (SCAlar DIStribution, 1D version; Sogachev et al., 2002, 2012) coupled with detailed biogenic emissions, chemistry and aerosol dynamics. SCADIS describes the exchange between the vegetative canopy and atmosphere by considering the vegetation as a multi-layer medium and implementing parameterizations for radiation transfer, drag forces on leaves and stomatal conductance. The particle deposition processes in SOSAA are treated in the same manner as in the study by Lauros et al. (2011) based on the parameterization by Petroff et al. (2008). The parameterization considers Brownian diffusion and takes into account the influence of leaves on particle interception, impaction and settling. The model has been applied extensively in different forest sites for various studies concerning biogenic emissions, chemistry and aerosol formation (e.g., Kúrten et al., 2011; Boy et al., 2013; Smolander et al., 2014; Mogensen et al., 2015; Zhou et al., 2015). Detailed model description is presented by Boy et al. (2011) and Zhou et al. (2014).

The model setup in this study was the same as in the study by Zhou et al. (2014) except that only kinetic nucleation 
mechanism was employed in aerosol dynamics simulation (Weber et al., 1997; see also Sect. S2 in the Supplement). Zhou et al. (2014) presented the ability of SOSAA to reconstruct new particle formation events at Hyytiälä, which was the same site as in this study. The model was initialized with vertical profiles describing the initial atmospheric state (see Appendix B) and aerosol size spectrum observed at the surface and run for a 10-day time period similarly to Lauros et al. (2011). The aerosol size distribution was initialized each day at 00:00 LT based on the measurements at $2 \mathrm{~m}$ height. The first day the concentration profile was assumed constant (the same as at $2 \mathrm{~m}$ height) up to determined nighttime stable boundary layer (SBL) height $(320 \mathrm{~m})$ and $10 \%$ of the concentration values within the SBL above this level. During the next days the concentration profile was taken constant as per measurements at $2 \mathrm{~m}$ level up to the maximum ABL height occurring during the previous day and $10 \%$ of the within SBL values above that level. The initialization during the first day corresponded to the conditions of horizontal advection with very different properties of the air above the SBL, whereas during the other days the nighttime residual layer was assumed to retain the same properties as the SBL. The implications of these two contrasting assumptions for ABL mixing and vertical transport of aerosols will be discussed in Sect. 3.4. For meteorology simulations $10 \mathrm{sec}$ time step was used along with the explicit forward in time integration method. The aerosol dynamics was simulated with $60 \mathrm{~s}$ time step.

\subsection{Lagrangian estimation of turbulent transfer time}

The Lagrangian stochastic (LS) simulations were used to estimate the turbulent transfer time. The conventional approach of using a LS model is to release particles at the surface point source and track their trajectories towards the point of interest forward in time (e.g., Wilson and Sawford, 1996). In case of horizontally homogeneous and stationary turbulence, the mean Lagrangian turbulent transfer time at the canopy top due to a sustained source located at height $z_{0}$ (near forest floor) can be described as

$\tau_{\mathrm{L}}(z)=\frac{1}{N} \sum_{i=1}^{N} \tau_{i}$,

where $\tau_{i}$ denotes the travel time of trajectory $i$ at the moment of intersection with observation height. For LS modeling the turbulence statistics such as the turbulent kinetic energy (TKE) and the vertical eddy diffusivity obtained from SOSAA were used to define the turbulent profiles of the dissipation rate of TKE and variances of the wind speed components.
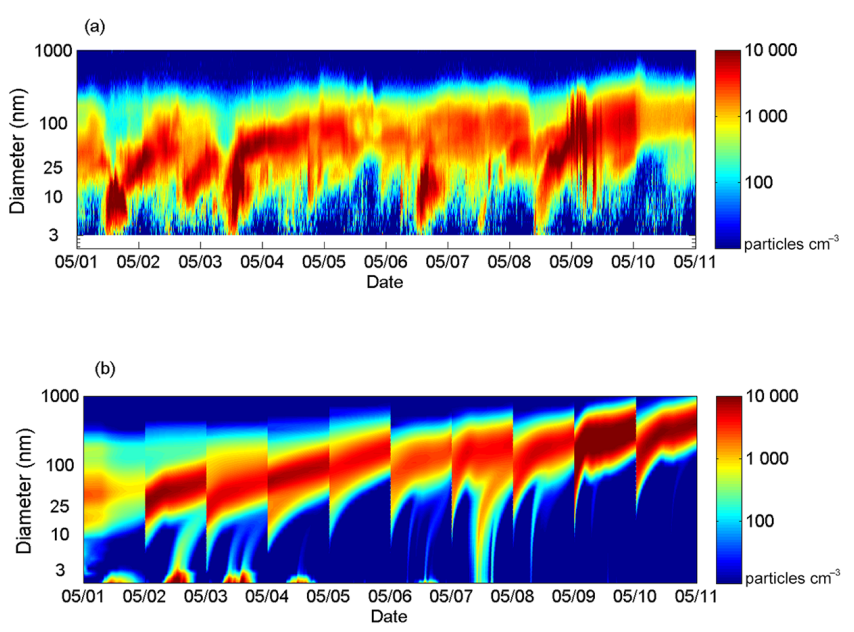

Figure 1. Aerosol size distribution at $2 \mathrm{~m}$ height during a 10-day period in May 2013 as (a) measured by the DMPS system and (b) predicted by the model SOSAA.

\section{Results}

The selected time period consisted of 10 days in May 2013, days of year (DOYs) 121 (1 May) to 130 (10 May). On several days clear particle formation patterns were observed at the smallest particle sizes around midday, with subsequent growth to larger particle sizes (Fig. 1). In all days significant aerosol dynamics was taking place in terms of particle growth. The model simulations reproduced the observed particle size distributions qualitatively; however, it was unable to reproduce the exact particle size distribution patterns. In particular, during days with new particle formation the observed nucleation modes were not as clear; the particle growth was also overestimated, which can be observed clearly during the second half of the period. With respect to condensational growth of aerosols and resulting patterns of aerosol particle distributions a sensitivity analysis was performed (Fig. S2). The results of the sensitivity analysis are summarized in the end of Sect. 3.

The ABL height varied between about 600 (DOY 130) and $1400 \mathrm{~m}$ (DOY 123) as the peak height during different days (Fig. 2a). The heat fluxes were the primary drivers of the ABL growth and buoyancy-driven TKE. The simulated latent and sensible heat fluxes corresponded well to those measured at the site (Fig. 2b, c), but the simulated TKE had weak correlation with the values observed above the canopy (Fig. S1 in the Supplement). We ascribe this to the limited ability of the 1-D model to reproduce the actual flow field at the site. However, for the current study it is more important to reproduce diurnal variation and dynamics of the $\mathrm{ABL}$, which is mainly driven by surface heating. The selected 10-day period showed significant variability in terms of aerosol and ABL dynamics and was therefore selected as the study case. 

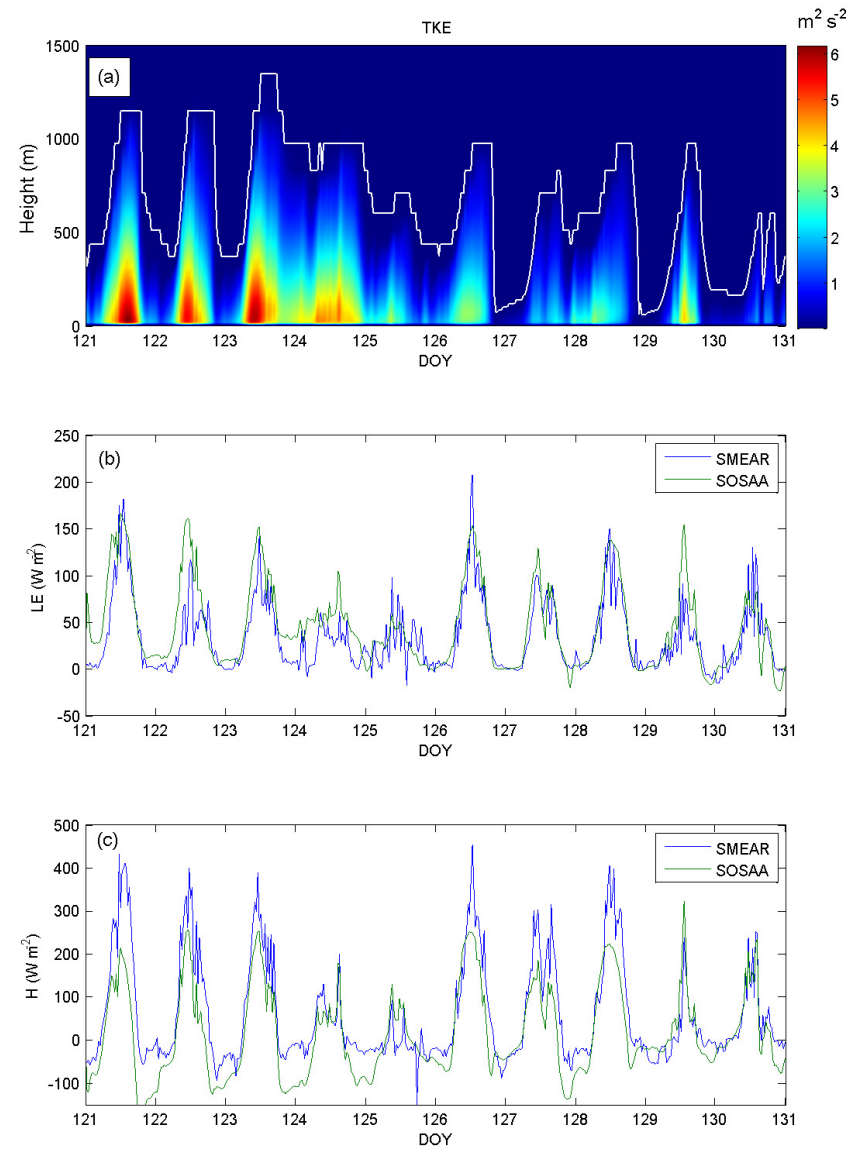

Figure 2. General meteorology: (a) TKE and ABL height, (b) latent heat flux LE and (c) sensible heat flux $H$ during a 10-day period in May 2013. SMEAR refers to measurements at the station.

\subsection{Aerosol dynamics and transport inside and above forest}

The particle conservation terms were evaluated inside the forest on 7 May (DOY 127) at 12:00 and 21:00 LT (UTC +2). At noon the particle size spectrum was bi-modal, with nucleation and larger particle modes, by evening the nucleation mode had grown and almost merged into a single mode at around $200 \mathrm{~nm}$ (Fig. 3a). The rate of change by each term (as defined by the terms in Eq. 4) showed large particle sink due to deposition, which was compensated by the transport term at noon (Fig. 3b). The aerosol dynamical term was dominated by the condensational growth term, except at sizes smaller than a few tens of nanometers where coagulation was also important and at smallest sizes were particles due to nucleation appeared. The aerosol dynamics reduced the particle number of small particles less than about $10 \mathrm{~nm}$ in diameter, adding particle counts at larger sizes. The aerosol dynamical terms were reflected in relatively similar pattern in particle storage change (defined by the first term of Eq. 4). The positive value of the storage term implies a decrease of par-

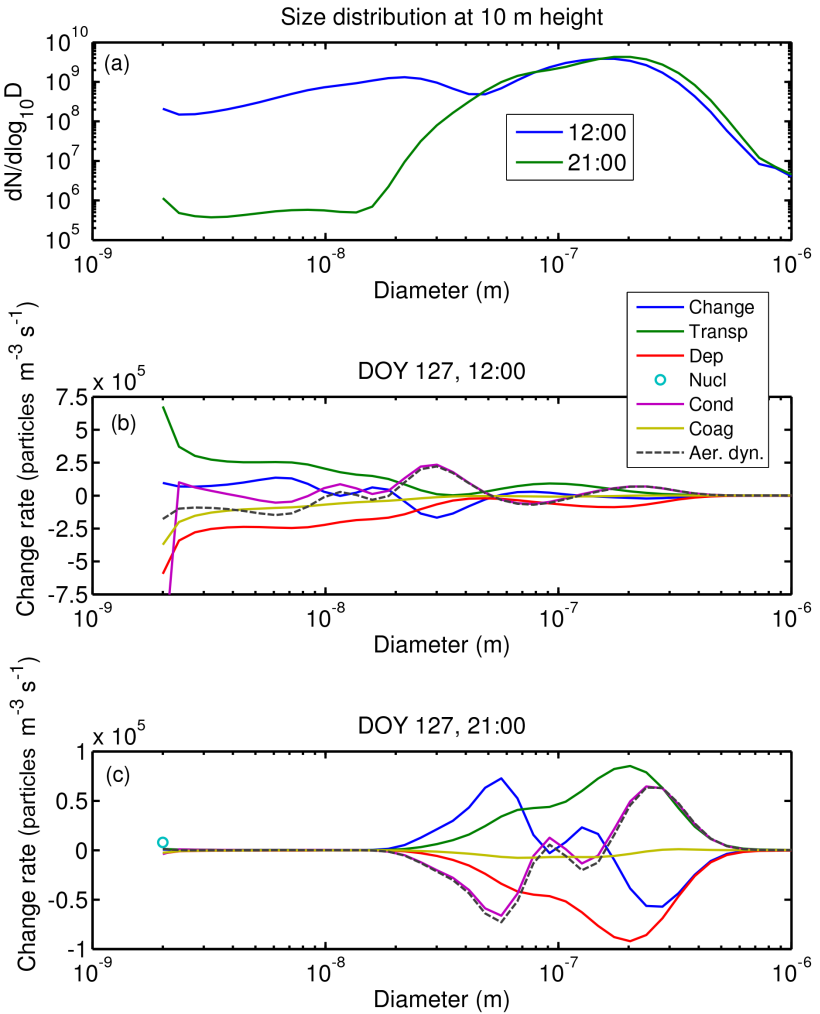

Figure 3. (a) Aerosol size distributions and the conservation terms on 7 May at (b) 12:00 LT (the values for nucleation and condensation terms at $2 \mathrm{~nm}$ are out of scale, being in absolute values about $1.3 \times 10^{6}$ particles $\mathrm{m}^{3} \mathrm{~s}^{-1}$ but opposite in sign) and (c) 21:00 LT as a function of particle size at $10 \mathrm{~m}$ height. The storage change (Change), (vertical) transport (Transp), particle deposition (Dep) and aerosol dynamical (Aer. Dyn.) terms are also used in Eq. (4). The aerosol dynamical term is the sum of the nucleation ( $\mathrm{Nucl}$ ), condensation growth (Cond) and coagulation (Coag) terms.

ticle concentration and a negative value an increase. In the evening at 21:00 LT the change rates of small particles (less than $20 \mathrm{~nm}$ ) were small due to low particle counts in this part of the size spectrum (Fig. 3a). The similarity (in magnitude, but opposite in sign) of aerosol deposition vs. transport and aerosol dynamical vs. storage change terms held also in the evening, leading us to conclude that particle loss due to deposition was mainly compensated by vertical transport and aerosol dynamical processes modified the concentration in time.

The aerosol concentration inside and above forest was homogeneous at noon and small vertical concentration gradients could not be observed from color presentation in Fig. 4a. The deposition pattern (dependence on particle size and height) was again similar to transport patterns (Fig. 4d and c). Aerosol dynamics affected the number concentration similarly throughout the column as presented in Fig. $4 \mathrm{~b}$ and e. The same qualitative conclusions held also for the evening time, 21:00 LT (not shown). 

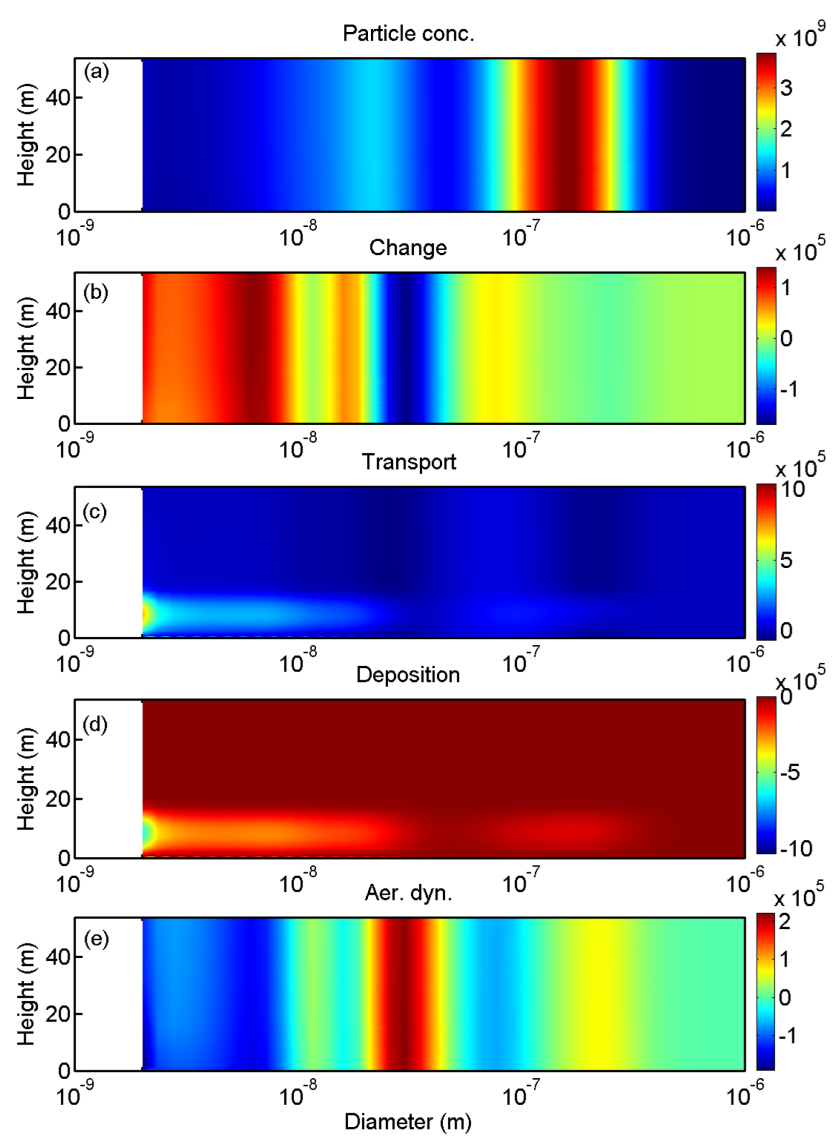

Figure 4. Vertical profiles of aerosol (a) number concentration (particles $\mathrm{m}^{-3}$ ) and conservation terms: (b) storage change (particles $\mathrm{m}^{-3} \mathrm{~s}^{-1}$ ), (c) transport (in particles $\mathrm{m}^{-3} \mathrm{~s}^{-1}$ ), (d) deposition (in particles $\mathrm{m}^{-3} \mathrm{~s}^{-1}$ ) and (e) aerosol dynamical (in particles $\mathrm{m}^{-3} \mathrm{~s}^{-1}$ ) on 7 May at 12:00 LT for particle size range from $2 \mathrm{~nm}$ to $1 \mu \mathrm{m}$.

When integrating the terms of the conservation equation (Eq. 4) from the surface up to the canopy top and normalizing with the concentration at the canopy top, one obtains change velocities as defined in Sect. 2.1. Such change velocities are comparable with the deposition velocity or the exchange velocity, which can be experimentally obtained from the flux measurements above the canopy. In terms of change velocities the deposition velocity (defined by Eq. 5) and the transport velocity (defined by Eq. 7 and equivalent to the exchange velocity in Eq. 8) appeared near symmetric for all particle sizes at noon (Fig. 5a). However, the correspondence was not exact, meaning that the flux defined at the canopy top did not correspond exactly to particle deposition. This was due to aerosol dynamics being responsible for additional sink inside the canopy for sizes up to $10 \mathrm{~nm}$, creating concentration decrease as well as additional downward particle transport to compensate for the loss. Much larger differences in the respective patterns were observed in the evening at 21:00 LT, especially at small particle sizes (Fig. 5b). This im-
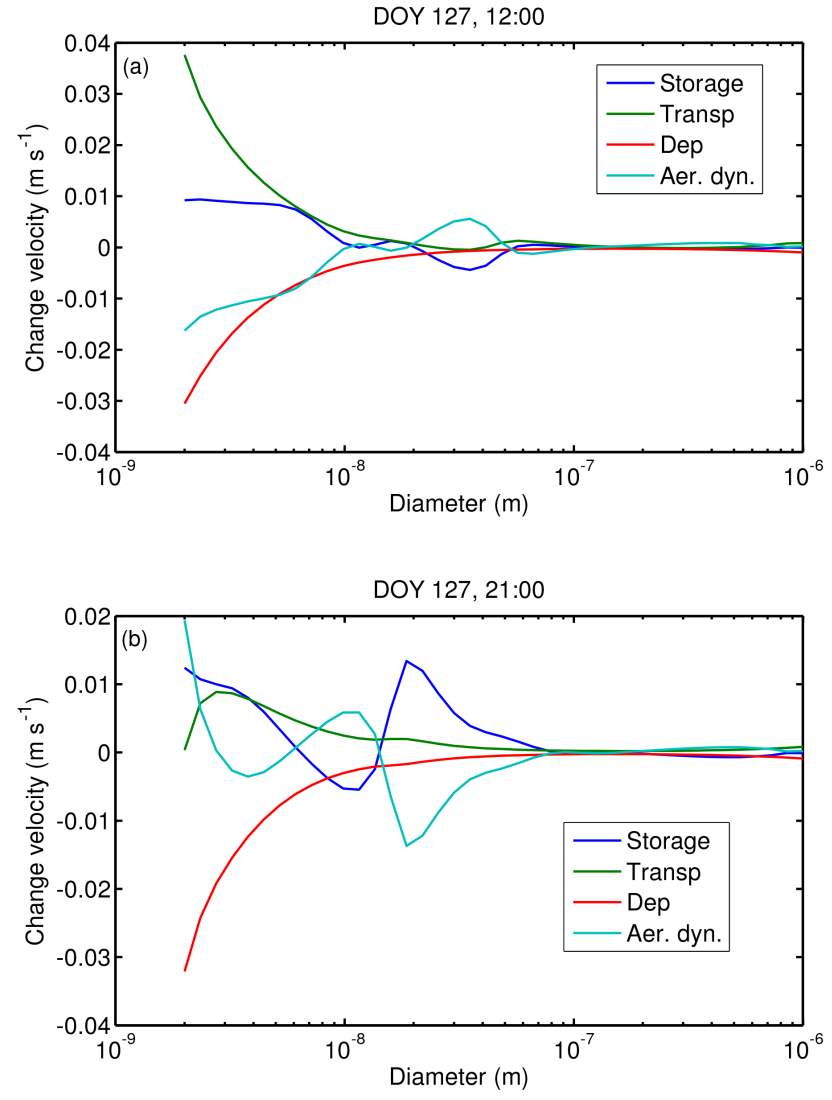

Figure 5. Integrated up to the canopy top conservation equation (Eq. 4) terms for the same periods as in Fig. 3a and b, normalized with the concentration at the canopy top.

plied a more complex relationship between particle source sink/terms (deposition and aerosol dynamics) and vertical mixing.

The vertical profiles of the aerosol dynamical term (normalized to simulated local concentrations, defining the local change rates) and the particle vertical fluxes (normalized with local concentration, defining the local exchange velocity) differed significantly for particle sizes and time of day (12:00 LT compared to 21:00 LT, 7 May), Fig. 6 upper and lower panels. The respective ABL heights were approximately 710 and $510 \mathrm{~m}$ according to the model results. At noon the particle deposition and aerosol dynamics led to vertical particle transport that depended on particle size and height. In the lower part of the ABL the small particles $(3$ and $10 \mathrm{~nm}$ ) were transported downward to compensate for deposition sink inside the forest and particle loss through aerosol dynamics. The $100 \mathrm{~nm}$ particles were transported downward throughout the atmospheric column. For particles of 30 and $300 \mathrm{~nm}$ size it was predominantly the aerosol dynamics that drove the vertical transport, leading mostly to upward particle flux at heights above forest. The particle concentration gradients (Fig. 6a/u) were consistent 

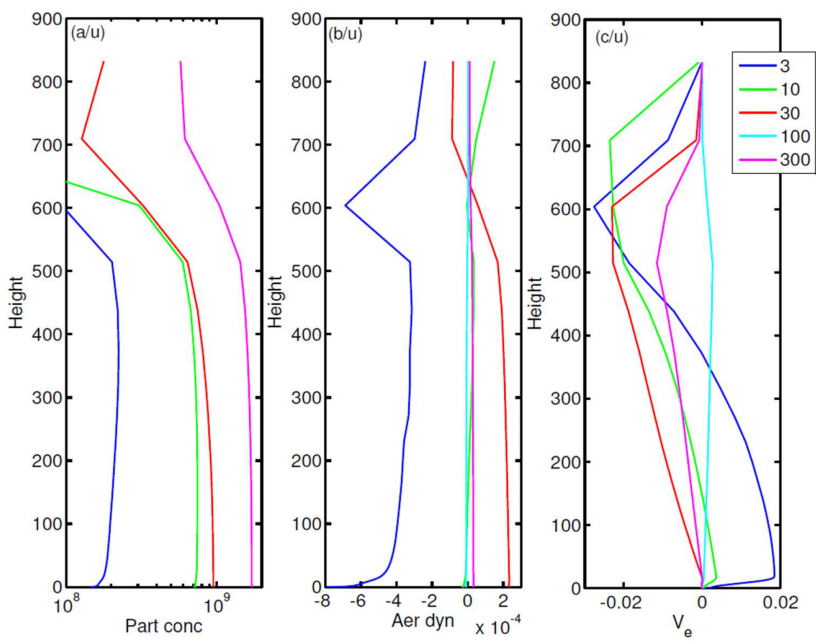

noon). Figure 6 illustrates complex dynamics between the aerosol sources and sinks and transport in the atmospheric column, leading to aerosol dynamical term and vertical exchange that can differ in sign as a function of height for a certain particle size (for example for $10 \mathrm{~nm}$ particles at 12:00 and 21:00 LT).

\subsection{Timescales of processes}

The importance of aerosol dynamics for particle exchange measurements has been frequently assessed by comparing the timescales of aerosol dynamical and transport processes. Figure 7 presents the timescales defined in Sect. 2.1 and compares those with the Lagrangian turbulent transfer timescale determined according to Sect. 2.3. The time of turbulent transfer within forest (simulated as the time for an air par-
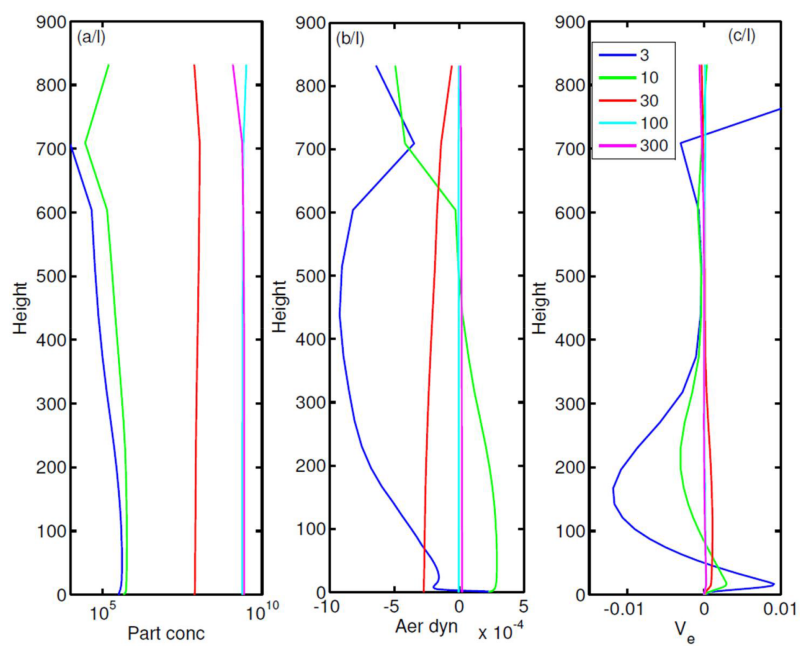

Figure 6. Vertical profiles of the (a) particle concentration (particles $\left.\mathrm{m}^{-3}\right)$, (b) change rate due to aerosol dynamics $\left(\mathrm{s}^{-1}\right)$, and (c) vertical exchange velocity defined to be positive for downward transport $\left(\mathrm{m} \mathrm{s}^{-1}\right)$ for selected particle sizes on 7 May at 12:00 LT (upper panels denoted by “/u”) and 21:00 LT (lower panels denoted by "/l"). For panels (b) and (c) normalization with local concentrations was used.

with the exchange velocities. In the evening, when the vertical transport was more limited due to moderately stable conditions (the Obukhov length defined by the fluxes at the canopy top being $L=+130 \mathrm{~m}$ ), the vertical profiles showed even more complex pattern (Fig. 6, lower panels). Particles with 3 and $10 \mathrm{~nm}$ in diameter were transported downward up to about $50-100 \mathrm{~m}$ height (to compensate for the loss inside the canopy), whereas above these heights up to about $500 \mathrm{~m}$ upward flux occurred to compensate for aerosol dynamical loss in the higher part of the atmospheric column. Note, however, that the concentration of small particles was very low in the evening (Fig. 6a/l). The larger particle sizes $(300 \mathrm{~nm})$ were little affected by the aerosol dynamics in the evening and downward transport occurred (in contrast to 

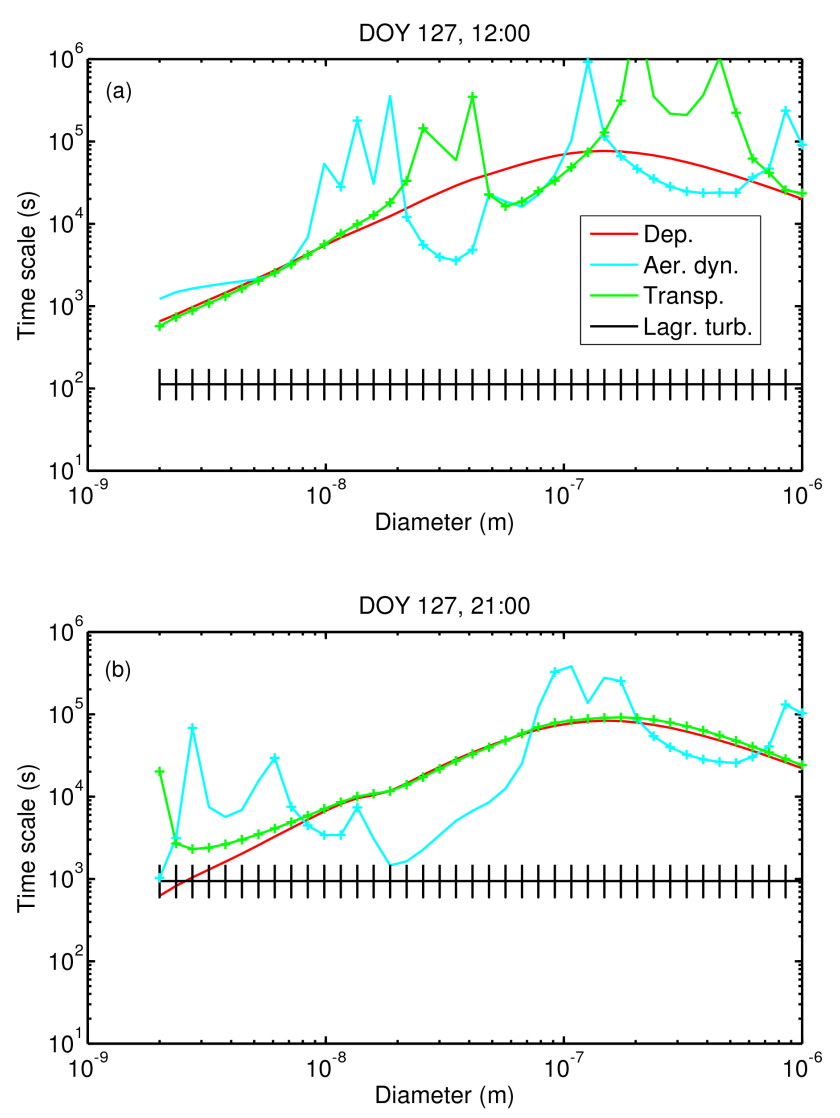

Figure 7. The timescales of deposition, aerosol dynamics and transport (equivalent to vertical exchange) as defined by Eq. (9) together with Eqs. (5), (6) and (7) at (a) 12:00 LT (the values for the transport term are out of scale at about 200 and $450 \mathrm{~nm}$, being about $+3.7 \times 10^{6}$ and $-1.05 \times 10^{6} \mathrm{~s}$, respectively) and (b) 21:00 LT on 7 May 2013. In addition the Lagrangian timescale for turbulent transfer (corresponding to aerodynamic resistance only) as simulated according to Eq. (10), is presented as the median air parcel travel time between the forest floor and the canopy top with upper and lower quartiles. The "+" sign reflects the positive sign of the respective term (the source), whereas no such sign infers the negative (sink) term.

fluxes. Figure 8 compares the change velocities defined in Sect. 2.1 to the respective deposition change velocities during the first day of the simulations, 1 May (DOY 121), and the following nucleation day, 2 May 2013 (DOY 122). These two days differ in terms of initialization of vertical aerosol profiles at midnight (see Sect. 2.2). During the first day the aerosol dynamics barely affected the particle concentrations inside the forest, but 100 and $300 \mathrm{~nm}$ sizes were affected strongly by vertical transport occurring during the mixed layer (ML) growth period prior to noon. The initial concentration profile during this day corresponded to the conditions of horizontal advection. During the second day the aerosol dynamical term exceeded the deposition term several times (Fig. 8c). The storage change varied in approximately the
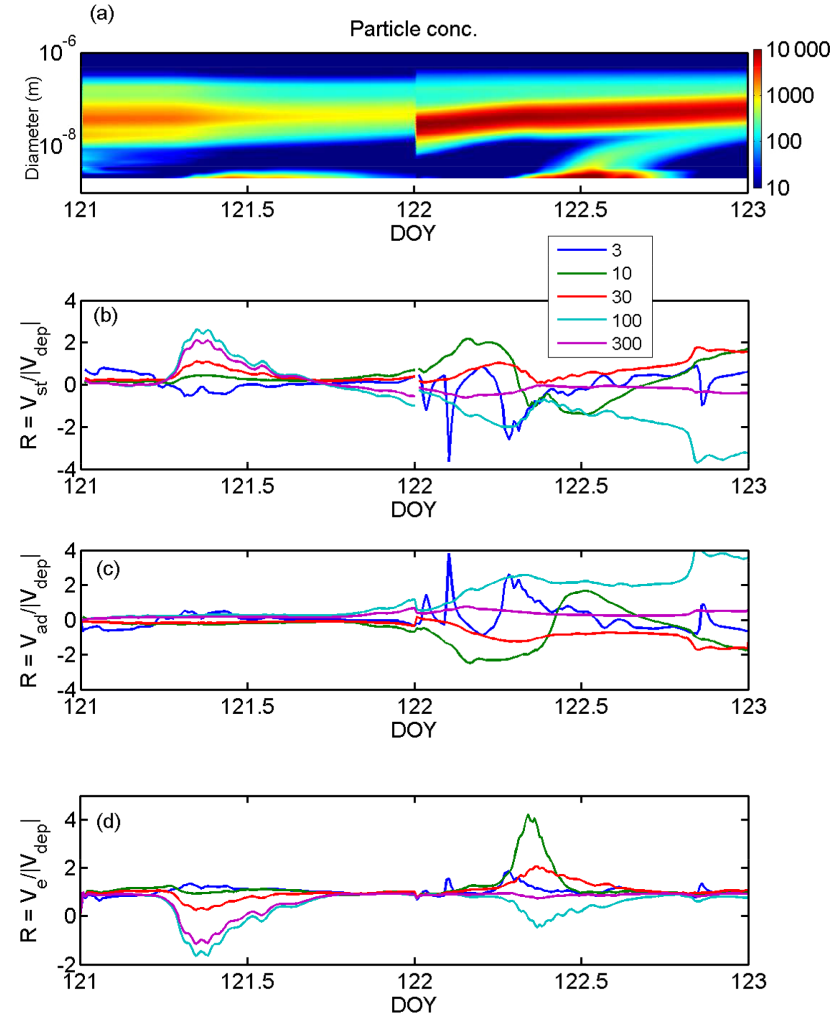

Figure 8. (a) Particle size spectrum and the change velocities (presented as the ratios to the absolute value of the deposition term) for selected particle sizes for (b) storage, (c) aerosol dynamics and (d) vertical exchange during 1 and 2 May (DOY 121 and 122) 2013.

same limits, and it is opposite in phase (Fig. 8b). The variation of the exchange velocity with respect to deposition was smaller (Fig. 8d), consistent with the analysis of Fig. 3 in which the vertical transport was the main mechanism compensating for aerosol loss due to deposition. Nevertheless, the magnitude of the exchange velocity can also differ several times compared to that of deposition. During the new particle formation and ABL growth period of the second day the vertical particle exchange showed downward transport of small particles (3, 10 and $30 \mathrm{~nm}$ ) and upward transport of $100 \mathrm{~nm}$ particles. In particular during the first day (DOY 121), the upward particle transport was synchronous with the storage change, i.e., the concentration decrease (Fig. 8b), referring to the dilution of concentration within the canopy. Downward transport of $10 \mathrm{~nm}$ particles during the second day in turn exceeded significantly the particle deposition. This particle size range was affected then by the aerosol dynamical term changing (from negative to positive) during the morning hours due to particle growth (Fig. 8c), which was due to the fact that $10 \mathrm{~nm}$ size was on the lower edge of the dominant mode of the particle size spectrum (Fig. 8a). Note also that the storage change of $10 \mathrm{~nm}$ particles was similar to the aerosol dynamical term (opposite in sign) and not to the ex- 
change velocity. Therefore the relatively large downward flux during the second day (DOY 122) was mainly driven by the aerosol dynamics occurring at night, whereas the growth of the ML initiated strong vertical mixing.

In order to understand overall trends and variability in aerosol dynamics and transport, the diurnal patterns of the averages together with the range of variation were presented in Fig. 9 for three particle sizes characterizing the nucleation $(10 \mathrm{~nm})$, Aitken $(50 \mathrm{~nm})$ and accumulation $(300 \mathrm{~nm})$ modes. For $50 \mathrm{~nm}$ particles the aerosol dynamics were a sink at night, whereas the condensational growth served as the source of $300 \mathrm{~nm}$ particles round the clock. The variation range of the aerosol dynamical term can be very large, indicating the role of ABL development during different days. Whereas the variation range of the aerosol dynamics and storage was large generally at night, the vertical exchange deviated from deposition mainly during the early morning SBL and further ABL growth period until noon (Fig. 9c). During this period the $50 \mathrm{~nm}$ particle fluxes were larger than induced by deposition, and during the ABL growth the $300 \mathrm{~nm}$ particle fluxes were lower than would have corresponded to deposition on average.

We further looked how different particle sizes were affected during different stages of the ABL state. At night the aerosol dynamics affected a wide range of particles and on average performed as the sink for particles less than $100 \mathrm{~nm}$ and the source for larger particles (Fig. 10c). The aerosol dynamical sink/source led primarily to particle concentration change. During the morning hours from sunrise until noon the ABL growth induced enhanced downward transport of about 30-200 nm particles, whereas vertical downward transport of larger particles was less than deposition sink (Fig. 10a). During the afternoon all the change velocities exhibited less variation compared to morning and night hours. Consequently deposition was also the best represented by the averages fluxes at the canopy top in the afternoon, with biggest deviation coinciding with the minimum in deposition velocity at around $100 \mathrm{~nm}$ (Fig. 10b). Figures 8, 9 and 10 (see also Fig. S3) illustrate that both the aerosol dynamics and $\mathrm{ABL}$ growth can strongly affect the vertical transport of aerosols and the fluxes above the canopy can deviate significantly from the deposition occurring within the canopy.

Due to instrumental limitations or by intention (frequently to obtain statistically significant particle counts in order to reduce particle flux random errors), a certain size interval of particles is measured. Figure 11 presents the vertical exchange velocity size-integrated values to represent the nucleation $(3-30 \mathrm{~nm})$, Aitken $(30-100 \mathrm{~nm})$ and accumulation (100-1000 nm) mode particles. During the first day with assumed conditions of horizontal advection the size-integrated particle fluxes showed clear upward transport during the morning hours for $30-100$ and $100-1000 \mathrm{~nm}$ size ranges. The same has also been observed from the measurements and interpreted as the upward transport due to ABL growth and resulting dilution of relatively particle-rich air within forest
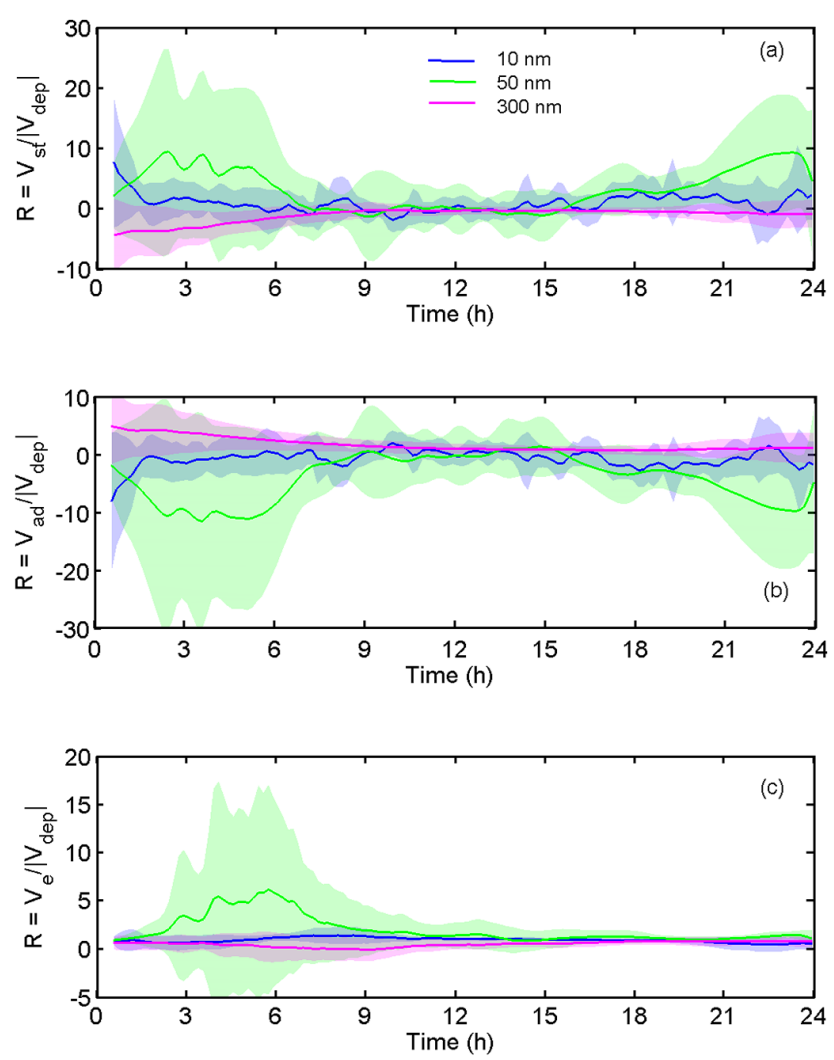

Figure 9. Diurnal variation of change velocity for (a) storage, (b) aerosol dynamics and (c) vertical exchange for selected particle sizes. The lines present the ratios of the average change velocities to the average deposition term according to $\frac{\langle V\rangle}{\langle| V_{\mathrm{dep}} \|}$ obtained from model simulations for each $10 \mathrm{~min}$ period and the shaded areas the variation range as $\pm \frac{\sigma_{V}}{\langle| V_{\mathrm{dep}} \|}$ around the averages.

with the particle-poor air transported down from aloft (e.g., Nilsson et al., 2001). The days with very large (both positive and negative) values of the exchange velocities compared to deposition velocities corresponded to the days with preceding very low ABL heights at nights (DOY 127, 129, 130). Therefore the ABL development can be identified as one of the main reasons for the large variation in vertical transport of particles. In case of experimental flux measurements the statistical uncertainty as well as natural variation originating from spatial heterogeneity and horizontal advection can additionally contribute to the variance of the calculated fluxes, leading to flux patterns with large variation, that are often difficult to interpret.

Table 1 presents the statistics of the fluxes at the canopy top (relative to deposition) for different particle sizes. Whereas for smaller particles $3-10 \mathrm{~nm}$ the time-averaged particle flux statistics converged to particle deposition within forest, for larger particles the fluxes (if measured by the micrometeorological technique) were biased in representing the particle deposition even on the average. The largest devia- 
Table 1. Statistics of the ratio of the flux at the canopy top to deposition sink integrated over the canopy over a 10-day period in May 2013. The average statistics $\left\langle V_{\mathrm{e}}\right\rangle$ and $\left\langle\left|V_{\mathrm{dep}}\right|\right\rangle$ were averaged over the simulation period first and then the ratio was found, whereas the percentile statistics apply for the ratios $\frac{V_{\mathrm{e}}}{\left|V_{\mathrm{dep}}\right|}$ obtained from model simulations for each 10 min period.

\begin{tabular}{lrrrrrrrrr}
\hline Particle size $(\mathrm{nm})$ & 3 & 10 & 30 & 100 & 300 & 850 & $3-30$ & $30-100$ & $100-1000$ \\
\hline$\left\langle V_{\mathrm{e}}\right\rangle$ & 0.90 & 0.99 & 1.36 & 2.09 & 0.53 & 0.82 & 1.11 & 1.99 & 0.66 \\
$\left\langle\left\|V_{\text {dep }}\right\|\right.$ & -0.24 & -0.18 & -0.32 & 0.15 & -1.30 & 0.20 & 0.33 & 0.70 & -0.76 \\
$Q_{5}$ & 0.77 & 0.87 & 0.93 & 0.82 & 0.32 & 0.73 & 0.97 & 0.95 & 0.56 \\
$Q_{25}$ & 0.97 & 1.00 & 1.06 & 0.94 & 0.85 & 0.92 & 1.06 & 1.04 & 0.86 \\
Median & 1.15 & 1.09 & 1.31 & 1.34 & 0.92 & 0.96 & 1.20 & 1.57 & 0.92 \\
$Q_{75}$ & 1.81 & 1.70 & 3.36 & 9.59 & 1.01 & 1.00 & 2.12 & 10.5 & 0.98 \\
$Q_{95}$ & & & & & & & & & \\
\hline
\end{tabular}

Table 2. Statistics of the ratio of the flux at the canopy top to deposition sink integrated over the canopy over a 10-day period in May 2013. For more details see Table 1. Morning refers to the time period from sunrise until noon, afternoon from noon until sunset and night from sunset until sunrise.

\begin{tabular}{lrrr|rrr|rrr}
\hline Time & \multicolumn{3}{c}{ Morning } & \multicolumn{3}{c}{ Afternoon } & \multicolumn{3}{c}{ Night } \\
\hline Particle size (nm) & $3-30$ & $30-100$ & $100-1000$ & $3-30$ & $30-100$ & $100-1000$ & $3-30$ & $30-100$ & $100-1000$ \\
\hline$\left\langle V_{\mathrm{e}}\right\rangle$ & 1.25 & 2.92 & 0.48 & 1.12 & 1.67 & 0.73 & 0.84 & 1.19 & 0.81 \\
$\left\langle V_{\text {dep }} \|\right.$ & 0.68 & 0.20 & -1.36 & 0.77 & 0.70 & 0.07 & -0.27 & 0.87 & -0.16 \\
$Q_{5}$ & 1.04 & 0.94 & 0.33 & 0.97 & 0.94 & 0.56 & 0.92 & 0.96 & 0.77 \\
$Q_{25}$ & 1.17 & 1.17 & 0.84 & 1.03 & 1.03 & 0.84 & 1.03 & 1.01 & 0.86 \\
Median & 1.46 & 2.96 & 0.91 & 1.13 & 1.40 & 0.91 & 1.11 & 1.17 & 0.93 \\
$Q_{75}$ & 2.21 & 29.6 & 0.98 & 1.69 & 7.21 & 0.99 & 3.85 & 3.04 & 0.96 \\
$Q_{95}$ & \multicolumn{7}{c}{} & &
\end{tabular}

tions of the particle fluxes from dry deposition sink occurred during the morning period when most intensive aerosol dynamics and ABL development took place (Table 2). Consistently with Fig. $10 \mathrm{~b}$ at that time $30-100 \mathrm{~nm}$ downward particle fluxes exceeded dry deposition and in the size range 100$1000 \mathrm{~nm}$ the downward fluxes accounted for approximately half of the deposition sink.

Finally, we performed sensitivity analysis of our simulations with respect to saturation concentration of condensing vapors, which affects the condensational growth of aerosols. Two additional cases with low-saturation vapor concentration (equivalent to more condensation) and high-saturation vapor concentration (equivalent to less condensation) were tested (Sect. S2). Whereas the high-saturation vapor concentration case led to less apparent nucleation mode in the particle size spectrum, the low-saturation vapor concentration led to more pronounced and clear particle growth patterns during the nucleation days (Fig. S2). The storage change, aerosol dynamics and exchange velocities were studied for given scenarios (Figs. S3-S5). The main difference observed was that in case of high-saturation vapor concentration due to slower growth of particles, the effect of aerosol dynamics persisted longer in the morning and affected the Aitken mode particles as represented by $50 \mathrm{~nm}$ (Fig. S4c) along with similar impact on exchange velocity that overestimated dry deposition for given particle size (Fig. S5c). However, as revealed by the sensitivity analysis of different scenarios, the overall qualitative behavior was not significantly different.

\subsection{Discussion of results}

\subsubsection{Aerosol dynamics and deposition}

The simulations have shown that aerosol dynamics can have significant impact on aerosol population depending on particle sizes. It is mainly the condensational growth that can increase or decrease the particle numbers at certain sizes depending on the shape of the particle size spectrum. The aerosol dynamical impact on particle concentration at certain sizes can be equal to or even significantly exceed in magnitude the particle loss due to deposition within the canopy. This is in particular true for particle sizes at which deposition rate is minimal. Consistently with our result, Pryor and Binkowski (2004) and Pryor et al. (2013) have found that frequently the timescales corresponding to particle deposition and aerosol dynamical processes are on the same order of magnitude and therefore induce the concentration change with comparable magnitude. Pryor et al. (2013) evaluated these timescales to be on the order of 1-10 h during the daytime in summer over a pine forest. In the current study we presented that the aerosol dynamical timescale can be from approximately half an hour to tens of hours. 

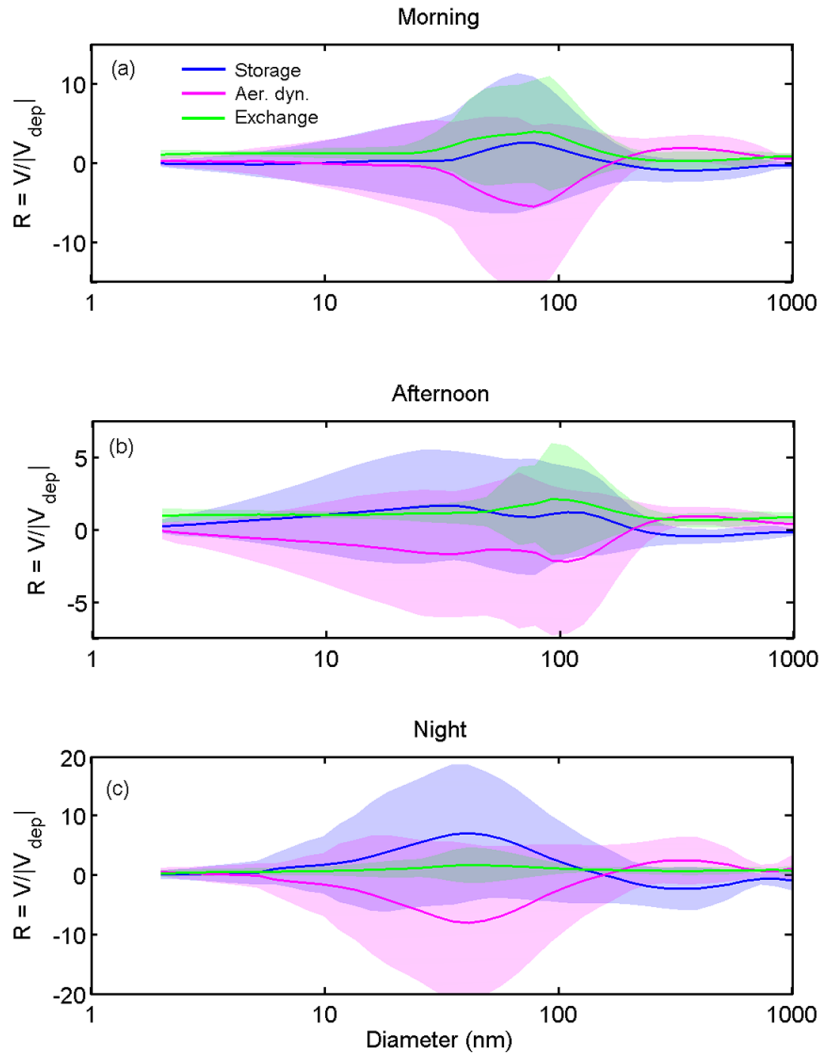

Figure 10. Variation of change velocities with particle size for (a) morning (from sunrise until noon), (b) afternoon (from noon until sunset) and (c) night (sun below horizon) periods: the blue line indicates the storage, magenta the aerosol dynamics and green the vertical exchange velocities. The lines present the ratios of the average change velocities to the average deposition term according to $\frac{\langle V\rangle}{\langle| V_{\mathrm{dep}} \|}$ obtained from model simulations for each $10 \mathrm{~min}$ period and the shaded areas are the variation range as $\pm \frac{\sigma_{V}}{\langle| V_{\text {dep }} \|}$ around the averages.

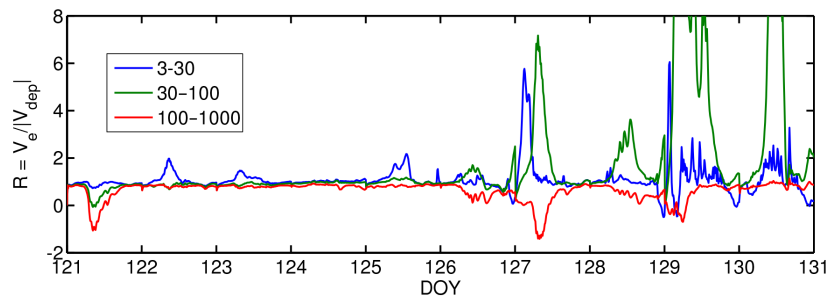

Figure 11. The exchange velocity $V_{\mathrm{e}}$ at the canopy top for selected particle size intervals during a 10-day period in May 2013 normalized with the absolute value of the deposition velocity $\left|V_{\text {dep }}\right|$. Peak values for the size range $30-100 \mathrm{~nm}$ at DOYs 129 and 130 were about 30-35.

The timescales of turbulent transfer and vertical transport were determined to be essentially different. The vertical transport of aerosols was limited by the deposition and aerosol dynamical processes and only at stable conditions could the turbulent transfer become limiting to vertical transport of particles. The turbulent transfer timescales estimated in the current study by using the LS trajectory simulations were on the order of minutes during the daytime and could be up to a few tens of minutes under SBL conditions. Some other definitions of the timescales have been used in the analysis of the significance of chemical transformation of reactive scalars during transport pathway between the measurement level and sources or sinks located primarily at leaf surface. Rinne et al. $(2000,2012)$ used the ratio of the observation height to the friction velocity as the estimate for the mixing timescale. Zelger et al. (1997) used the definitions of Eulerian and Lagrangian turbulent timescales to characterize the turbulent transfer within and above forest. Holzinger et al. (2005) instead used the estimate of the residence time and obtained the value about $1.5 \mathrm{~min}$ for daytime conditions. The Lagrangian turbulent transfer times obtained in this study were consistent with the previous studies including the timescales obtained by the same approach by Rannik et al. (2009b).

\subsubsection{Dynamics within ABL}

The timescales of aerosol deposition and dynamics are much longer than the turbulent transfer times within the forest canopy. Therefore, one would expect a minor impact of aerosol dynamics on particle population during the vertical transfer within forest under most of the observation conditions and a relatively good vertical mixing of aerosols within and above forest. Nevertheless, we have seen in the current study that the vertical fluxes at the canopy top can deviate significantly from what would be expected from dry deposition only. From current model simulations we have seen that the aerosol dynamics is an important mechanism of aerosol transformation throughout the ABL, whereas the aerosol deposition occurs only inside the forest canopy. In addition, the impact of aerosol dynamics is height dependent. Within the canopy the emissions of the precursor gases for particle condensational growth (the volatile organic compounds) occur. The dominant condensing compounds are the $\mathrm{OH}$ oxidation products of monoterpenes, which form during the transport pathway from inside the forest to higher levels in the ABL. The concentrations of the condensing compounds are therefore larger within and immediately above the canopy and decrease with height. Such height dependence of the condensational growth of particles can lead to modification of concentration gradient and vertical flux profile. Even though the atmospheric mixing is fast compared to the above-discussed processes, we believe it is the extensive source/sink term by aerosol dynamics that operates throughout the atmospheric column (compared to the impact of deposition inside the canopy only) and can thus create significant vertical flux divergence and even upward particle transport.

The concentration time change, when summed up from the surface up to the measurement level, is called the stor- 
age term and commonly accounted for in estimation of the net ecosystem exchange of carbon dioxide from the EC flux measurements (e.g., Foken et al., 2012). Such an approach inherently assumes that the storage change results from the source/sink activity below the observation level. Rannik et al. (2009a) studied the relevance of the storage term in estimation of the dry deposition from particle flux measurements. They concluded that in the case of aerosol particles the relevance of the storage term could not be established because of the different physical reasons for the concentration change during different phases of diurnal development of the ABL. This study supports the conclusion with the observation that the particle concentration change is primarily in correlation with the aerosol dynamics and the change occurs throughout the ABL. Therefore the particle storage change (which corresponds to accumulation or depletion) is not in general the sole component of the particle conservation equation that could help to improve particle deposition estimation from the flux measurements carried out above forest.

\subsubsection{Upward particle fluxes}

Particle fluxes determined by the micrometeorological techniques show typically large variability in magnitude as well as in sign. Occurrence of upward particle fluxes has been frequently reported in the literature (Pryor et al., 2007; Grönholm et al., 2007; Whitehead et al., 2010; Pryor et al., 2013). Even after careful classification of observations according to wind direction in order to remove the cases possibly affected by anthropogenic emissions, flux observation analyses by Pryor et al. (2008) revealed significant fraction of observations indicating emission. The upward particle flux values can be the result of large random uncertainty or caused by upward particle transport due to physical processes. Random flux errors of particle fluxes are due to stochastic nature of turbulence, instrumental noise and (limited) counting statistics of aerosol particles. The major source of the random uncertainty of particle flux estimates is the non-stationarity of particle concentration as well as its flux (for flux random uncertainties see Fairall, 1984). The particle fluxes have typically large statistical uncertainty, on the order of $100 \%$ and more (Pryor et al., 2008; Rannik et al., 2003); therefore, it is frequently difficult to determine whether the calculated upward particle occurrence reflects the true transport or was obtained by chance. Pryor et al. (2008) investigated thoroughly the distribution and significance of upward fluxes as well as the relevance of several physical mechanisms that cause them by taking into account the error estimates of fluxes. They came to the conclusion that several possible physical mechanisms were responsible for upward particle transport including the entrainment of particle-free air from above during the intensive ABL growth periods. Whitehead et al. (2010) observed similar systematic pattern over a tropical rainforest in case of supermicron particles. Upward particle fluxes were also observed on seasonal average diurnal patterns by Ran- nik et al. (2009a) in the statistical analysis of long-term particle flux measurements over a pine forest, confirming that the phenomenon is common over a long period of time.

Nilsson et al. (2001) also associated the occurrence of upward particle fluxes to the solar radiation increase and boundary layer development. In addition, they studied the evolution of the Aitken and accumulation mode particle concentrations in the ML during the ABL growth and inferred the particle concentrations being entrained by using a simple ML growth model based on thermodynamical considerations. The model explained well the ML height as well as the particle concentration evolution. The entrained particle concentrations were determined to be virtually from 0 to $40 \%$ of the close-tosurface values, indicating that nighttime horizontal advection was a dominating process at the site affecting the vertical profiles of aerosols above the SBL. The initialization of the aerosol concentration profiles during the first day of simulations in the current study represent such advective conditions and resulted in strong upward particle transport during the early morning ML growth. Whereas the nighttime advection can be typical to SMEAR II site, it is certainly a sitespecific phenomenon and therefore for the rest of the period we intended to use the initialization of profiles with uniform particle concentration up to the residual layer height. Therefore our simulation results for the first day represent the conditions characteristic to strong horizontal advection and are during the rest of the days expected to underestimate the vertical transport due to ML growth.

Gordon et al. (2011) observed major fraction $(60 \%)$ of upward particle fluxes for size interval $18-450 \mathrm{~nm}$ above a mixed forest in Ontario, Canada, using the EC technique. The upward particle flux rate was highest for $75 \mathrm{~nm}$ particles. One of the mechanisms for upward fluxes was the entrainment of clean air from aloft as discussed previously. As an additional mechanism, the authors proposed the slowest growth rate of this particle size, suggesting that the authors referred to the aerosol dynamics as one of the reasons.

Pryor et al. (2013) also suggested the depletion mechanism as the most common cause of the upward fluxes above a sparse pine forest during the morning hours. Later in the day the authors attributed the upward fluxes of sub- $30 \mathrm{~nm}$ particles to the growth of the newly formed particles by condensation of the biogenic volatile organic compounds (BVOCs). All the mechanisms as the reasons for upward particles fluxes discussed here appear to be the plausible reasons according to our model simulations and can dominate depending on location, emission rates of BVOCs, time of day, particle size and possibly some other factors. The results of the current study identified the aerosol dynamics as one of the main mechanisms causing upward transport of particles with $30 \mathrm{~nm}$ in diameter and larger. 


\subsubsection{Fluxes of above $100 \mathrm{~nm}$ particles}

Our results have shown that the aerosol and ABL dynamics can introduce significant systematic deviation of the exchange velocities above the canopy from dry deposition on the average. For around $100 \mathrm{~nm}$ particles the fluxes above the canopy exceeded the dry deposition sink and for larger than $100 \mathrm{~nm}$ the deposition was poorly characterized by the fluxes above the canopy (see Table 1). The range of the flux to deposition ratio varied from negative to positive values, being especially large for particles about $100 \mathrm{~nm}$, which coincides with the minimum of the particle deposition rate at this size. The median values presented in Table 1 were closer to unity than the averages. This implies that the averages are affected by extreme values corresponding to certain dynamical conditions occurring in the ABL. Such conditions certainly can take place in the real atmosphere. The fact that the median exchange velocities represent better deposition than the time average indicates that the median values are more robust statistics than the averages and should be perhaps used in representing the particle exchange instead of averages.

We note that the results based on model simulations were free of statistical uncertainty introduced by random errors to experimentally determined fluxes. Rannik et al. (2003) used a semi-empirical model to explain the size-integrated particle flux measurements performed at the same site with our model simulations. The model appeared to explain well the flux observation with particle population mainly consisting of below $100 \mathrm{~nm}$ particles. Deposition velocities for above $100 \mathrm{~nm}$ sizes were very uncertain. The authors proposed several reasons why the model was not able to explain the observations: presence of a mechanism controlling deposition of above $100 \mathrm{~nm}$ particles not described by the semi-empirical model as well as several other reasons such as temporary pollution sources in the measurement source area. The possible reasons of meteorological origin were suggested to be horizontal advection of particle concentration, boundary layer growth and concentration dilution, and roll circulation in the ABL (e.g., Buzorius et al., 2001). This study has shown that such apparent uncertainty in deposition pattern of above $100 \mathrm{~nm}$ particles could be the case even in horizontally homogeneous conditions due to aerosol dynamical and $\mathrm{ABL}$ development processes.

\section{Conclusions}

Simulations performed by the model SOSAA coupling turbulent exchange within the ABL with detailed atmospheric chemistry and aerosol dynamics indicated that the aerosol dynamics is strongly size dependent but a significant source/sink term to aerosol concentration throughout the atmospheric column. Whereas the vertical transport mostly compensates for particle loss inside the canopy due to the deposition, the aerosol dynamics leads to the concentration changes in the whole ABL. However, during the periods of intensive aerosol dynamics when new particle formation frequently occurs, the particle deposition and aerosol dynamics together with ABL development leads to complicated vertical transport patterns. For small particles (up to a few tens of nanometers) the deposition sink is relatively strong (compared to the aerosol dynamics) and the downward fluxes were predicted in the lower ABL. However, for some particle size ranges, depending on the aerosol dynamical processes, the stronger aerosol dynamical source inside and above forest (compared to higher ABL) can lead to upward particle transport such that the vertical fluxes above the canopy might not be coherent with dry deposition under such conditions. We have also observed that the ABL dynamics occasionally lead to upward particle transport which can be interpreted as the transport due to dilution of relatively particle-rich air within forest with the particle-poor air transported down from aloft during the active $\mathrm{ABL}$ growth phase.

The simulated turbulent transfer timescales inside the forest were much shorter than the timescales of deposition and aerosol dynamics for all sizes except the smallest at around $3 \mathrm{~nm}$. In spite of efficient mixing inside the canopy, the particle fluxes at the canopy top can deviate from the deposition rates inside forest. This is due to the transformation of aerosol concentration throughout the atmospheric column resulting in the complicated pattern of particle vertical transport. Therefore, the within-canopy deposition and transformation processes do not determine solely the particle vertical transport within and above the canopy and the respective timescales are not sufficient to determine whether the aerosol dynamics can cause significant particle flux divergence below the measurement level.

We conclude that under dynamical conditions studied here the particle fluxes above the forest canopy occasionally deviated from the particle dry deposition sink inside the forest canopy. Such deviations can be very large and for certain particle sizes even systematic after performing diurnal averaging of results. 
Appendix A: Description of measurements at SMEAR II

The SMEAR II (Station for Measuring Forest EcosystemAtmosphere Relations) field measurement station is located in Hyytiälä, Southern Finland $\left(61^{\circ} 51^{\prime} \mathrm{N}, 24^{\circ} 17^{\prime} \mathrm{E}\right.$; $181 \mathrm{~m}$ a.s.l.). The station is located in the area covered mainly by pine-dominated forests. The dominant height of the stand near the measurement tower was about $20 \mathrm{~m}$ in 2013. The main canopy at the site is characterized by the total leaf area index $(\mathrm{LAI}) \sim 6.5 \mathrm{~m}^{2} \mathrm{~m}^{-2}$ and stand density $1400 \mathrm{ha}^{-1}$ (Launiainen et al., 2011). The forest floor vegetation is relatively low (mean height $\sim 0.2-0.3 \mathrm{~m}$ ) but dense (total LAI $\sim$ $1.5 \mathrm{~m}^{2} \mathrm{~m}^{-2}$ ). However, in model setup a beta distribution of LAD was used that matched to observed turbulence statistics in and above the canopy and the forest floor vegetation as a separate layer was neglected (Boy et al., 2011). A more detailed description of the station and the measurements can be found in Hari and Kulmala (2005).

Turbulent fluxes of momentum, heat, $\mathrm{CO}_{2}$ and $\mathrm{H}_{2} \mathrm{O}$ were measured by means of the EC technique. The system, located at $23 \mathrm{~m}$ height above the ground on the top of a scaffolding tower, included an ultrasonic anemometer (Solent Research HS1199, Gill Ltd., Lymington, Hampshire, England) to measure the three wind velocity components and the sonic temperature, a closed-path infrared gas analyzer (LI-6262, LiCor Inc., Lincoln, NE, USA) that measured the $\mathrm{CO}_{2}$ and $\mathrm{H}_{2} \mathrm{O}$ concentrations. The data were sampled at $21 \mathrm{~Hz}$, and a 2-D rotation of sonic anemometer wind components and filtering to eliminate spikes were performed according to standard methods (e.g., Aubinet et al., 2000). The high-frequency flux attenuation was corrected by using empirical transfer functions and co-spectral transfer characteristics (Mammarella et al., 2009).

Aerosol size distribution (from $3 \mathrm{~nm}$ to $1 \mu \mathrm{m}$ ) measurements were performed using a differential mobility particle sizer (DMPS) system. The aerosol was sampled from inside the forest at $2 \mathrm{~m}$ height. Details of the DMPS measurement system are presented in Aalto et al. (2001).

\section{Appendix B: Initialization of model SOSAA}

The chemistry scheme employed by the model for this study included the relevant Master Chemical Mechanism (MCM) chemical paths (Jenkins et al., 1997, 2003; Saunders et al., 2003) for the following parent molecules: methane, methanol, formaldehyde, acetone, acetaldehyde, MBO, isoprene, $\alpha$-pinene, $\beta$-pinene, limonene and betacaryophyllene. For other emitted organic compounds including myrcene, sabinene, 3-carene, ocimene, cineole and "other" monoterpenes, and farnesene and "other" sesquiterpenes, the MCM chemistry paths are not available and we thus included their first-order oxidations with $\mathrm{OH}, \mathrm{O}_{3}$ and $\mathrm{NO}_{3}$. For the reactions of the stabilized Criegee intermediates (sCI) from $\alpha$ - and $\beta$-pinene and limonene, we used the rates from Mauldin III et al. (2012), similar to "Scenario C" in Boy et al. (2013). For the sCI from isoprene, we used the rates from Welz et al. (2012) as done in "Scenario D" in Boy et al. (2013). Sulfuric acid and nitric acid were removed from the gas phase based on the condensation sinks calculated from background aerosol loading.

There was no specific initialization of chemistry state for the model (all variables were initialized as 0 while created). Exceptions were the passive tracer concentrations $\left(\mathrm{CO}_{2}, \mathrm{NO}\right.$, $\mathrm{NO}_{2}, \mathrm{SO}_{2}$ and $\mathrm{O}_{3}$ ), which were initialized with measurements. The concentrations of these five passive tracers were always read in from measurements during the simulation. The time resolution of input data was half an hour and the data were linearly interpolated for each time step in the model run. The vertical profiles of the particle concentrations were initialized each night as described in Sect. 2.2.

Global short-wave radiation, top boundary temperature, humidity and wind speed were fixed to inputs throughout simulation. The global short-wave radiation was measured at SMEAR II. Temperature, humidity and wind speed at the top boundary were based on ECMWF reanalysis data.

The initial temperature profile was assumed linear, using the input top border temperature and input temperature gradient. The wind profile was set using the logarithmic wind law, the roughness and wind speed at the top boundary. Initial humidity was taken constant throughout the ABL and the heat fluxes and TKE were set to 0 . Mixing length was initialized as $l=0.40 \frac{z+z_{0}}{1+0.016 z}$.

At the lower boundary, soil humidity for the uppermost layer was set to $0.2 \mathrm{~kg} \mathrm{~kg}^{-1}$. Soil temperature was set to $-2^{\circ}$ from air temperature at the lowest level and leaf temperature was set equal to air temperature. Heat flux to the soil was based on the measurements from the SMEAR II station throughout simulations. 


\section{The Supplement related to this article is available online at doi:10.5194/acp-16-3145-2016-supplement.}

Acknowledgements. This work was supported by the Academy of Finland (project No. 118780 and 127456). ICOS (271878), ICOS-Finland (281255) and ICOS-ERIC (281250), and Nordic Center of Excellence, CRAICC, are gratefully acknowledged for funding this work. This work was also supported by institutional research funding (IUT20-11) of the Estonian Ministry of Education and Research. We further thank Helsinki University Centre for Environment (HENVI) and the Academy of Finland Centre of Excellence program (project no. 1118615). The CSC-IT center, Finland, is acknowledged for providing the computing service.

Edited by: R. MacKenzie

\section{References}

Aalto, P., Hämeri, K., Becker, E., Weber, R., Salm, J., Mäkelä, J. M., Hoell, C., O’Dowd, C. D., Karlsson, H., Hansson, H.C., Väkevä, M., Koponen, I. K., Buzorius, G., and Kulmala, M.: Physical characterization of aerosol particles during nucleation events, Tellus, 53B, 344-358, 2001.

Aubinet, M., Grelle, A., Ibrom, A., Rannik, Ü., Moncrieff, J., Foken T., Kowalski, A. S., Martin, P. H., Berbigier, P., Bernhofer, Ch., Clement, R., Elbers, J., Granier, A., Grünwald, T., Morgenstern, K., Pilegaard, K., Rebmann, C., Snijders, W., Valentini, R., and Vesala, T.: Estimates of the annual net carbon and water exchange of European forests: the EUROFLUX methodology, Adv. Ecol. Res., 30, 113-175, 2000.

Boy, M., Sogachev, A., Lauros, J., Zhou, L., Guenther, A., and Smolander, S.: SOSA - a new model to simulate the concentrations of organic vapours and sulphuric acid inside the ABL Part 1: Model description and initial evaluation, Atmos. Chem. Phys., 11, 43-51, doi:10.5194/acp-11-43-2011, 2011.

Boy, M., Mogensen, D., Smolander, S., Zhou, L., Nieminen, T., Paasonen, P., Plass-Dülmer, C., Sipilä, M., Petäjä, T., Mauldin, L., Berresheim, H., and Kulmala, M.: Oxidation of $\mathrm{SO}_{2}$ by stabilized Criegee intermediate $(\mathrm{sCI})$ radicals as a crucial source for atmospheric sulfuric acid concentrations, Atmos. Chem. Phys., 13, 3865-3879, doi:10.5194/acp-13-3865-2013, 2013.

Buzorius, G., Rannik, Ü., Nilsson, D., and Kulmala, M.: Vertical fluxes and micrometeorology during aerosol particle formation events, Tellus B, 53, 394-405, 2001.

Fairall, C. W.: Interpretation of eddy-correlation measurements of particulate deposition and aerosol flux, Atmos. Environ., 18, 1329-1337, 1984.

Foken, T., Aubinet, M., and Leuning, R.: The Eddy Covariance Method, in: Eddy Covariance - A Practical Guide to Measurement and Data Analysis, edited by: Aubinet, M., Vesala, T., and Papale, D., Springer, doi:10.1007/978-94-007-2351-1, 2012.

Gordon, M., Staebler, R. M., Liggio, J., Vlasenko, A., Li, S.-M., and Hayden, K.: Aerosol flux measurements above a mixed forest at Borden, Ontario, Atmos. Chem. Phys., 11, 6773-6786, doi:10.5194/acp-11-6773-2011, 2011.
Grönholm, T., Aalto, P. P., Hiltunen, V., Rannik, Ü., Rinne, J., Laakso, L., Hyvönen, S., Vesala, T., and Kulmala, M.: Measurements of aerosol particle dry deposition velocity using the relaxed eddy accumulation technique, Tellus B, 59, 381-386, doi:10.1111/j.1600-0889.2007.00268.x, 2007.

Hari, P. and Kulmala, M.: Station for measuring ecosystematmosphere relations (SMEAR II), Boreal Environment Res., 10, 315-322, 2005.

Hinds, W. C.: Aerosol Technology: Properties, Behavior, and Measurement of Airborne Particles, John Wiley and Sons, New York, 1982.

Holzinger, R., Lee, A., Paw, K. T., and Goldstein, U. A. H.: Observations of oxidation products above a forest imply biogenic emissions of very reactive compounds, Atmos. Chem. Phys., 5, 67-75, doi:10.5194/acp-5-67-2005, 2005.

Jenkin, M. E., Saunders, S. M., and Pilling, M. J.: The tropospheric degradation of volatile organic compounds: a protocol for mechanism development, Atmos. Environ., 31, 81-104, 1997.

Jenkin, M. E., Saunders, S. M., Wagner, V., and Pilling, M. J.: Protocol for the development of the Master Chemical Mechanism, MCM v3 (Part B): tropospheric degradation of aromatic volatile organic compounds, Atmos. Chem. Phys., 3, 181-193, doi:10.5194/acp-3-181-2003, 2003.

Kurtén, T., Zhou, L., Makkonen, R., Merikanto, J., Räisänen, P., Boy, M., Richards, N., Rap, A., Smolander, S., Sogachev, A., Guenther, A., Mann, G. W., Carslaw, K., and Kulmala, M.: Large methane releases lead to strong aerosol forcing and reduced cloudiness, Atmos. Chem. Phys., 11, 6961-6969, doi:10.5194/acp-11-6961-2011, 2011.

Launiainen, S., Katul, G. G., Kolari, P., Vesala, T., Hari, P.: Empirical and optimal stomatal controls on leaf and ecosystem level $\mathrm{CO}_{2}$ and $\mathrm{H}_{2} \mathrm{O}$ exchange rates, Agr. Forest Meteorol., 151, 1672 1689, doi:10.1016/j.agrformet.2011.07.001, 2011.

Lauros, J., Sogachev, A., Smolander, S., Vuollekoski, H., Sihto, S.L., Mammarella, I., Laakso, L., Rannik, Ü., and Boy, M.: Particle concentration and flux dynamics in the atmospheric boundary layer as the indicator of formation mechanism, Atmos. Chem. Phys., 11, 5591-5601, doi:10.5194/acp-11-5591-2011, 2011.

Mammarella, I., Launiainen, S., Gronholm, T., Keronen, P., Pumpanen, J., Rannik, Ü., and Vesala, T.: Relative humidity effect on the high frequency attenuation of water vapour flux measured by a closed-path eddy covariance system, J. Atmos. Ocean. Tech., 26, 1856-1866, 2009.

Mauldin III, R. L., Berndt, T., Sipilä, M., Paasonen, P., Petäjä, T., Kim, S., Kurtén, T., Stratmann, F., Kerminen, V.-M., and Kulmala, M.: A new atmospherically relevant oxidant, Nature, 488, 193-196, doi:10.1038/nature11278, 2012.

Mogensen, D., Gierens, R., Crowley, J. N., Keronen, P., Smolander, S., Sogachev, A., Nölscher, A. C., Zhou, L., Kulmala, M., Tang, M. J., Williams, J., and Boy, M.: Simulations of atmospheric $\mathrm{OH}, \mathrm{O}_{3}$ and $\mathrm{NO}_{3}$ reactivities within and above the boreal forest, Atmos. Chem. Phys., 15, 3909-3932, doi:10.5194/acp15-3909-2015, 2015.

Monteith, J. L. and Unsworth, M. H.: Principles of Environmental Physics, Edward Arnold, London, 1990.

Nilsson, E. D., Rannik, Ü., Kulmala, M., Buzorius, G., and O'Dowd, C. D.: Effects of continental boundary layer evolution, convection, turbulence and entrainment, on aerosol formation, Tellus B, 53, 441-461, 2001. 
Petroff, A. and Zhang, L.: Development and validation of a size-resolved particle dry deposition scheme for application in aerosol transport models, Geosci. Model Dev., 3, 753-769, doi:10.5194/gmd-3-753-2010, 2010.

Petroff, A., Mailliat, A., Amielh, M., and Anselmet, F.: Aerosol dry deposition on vegetative canopies. Part II: A new modelling approach and applications, Atmos. Environ., 42, 3654-3683, 2008.

Pryor, S. C. and Binkowski, F. S.: An analysis of the time scales associated with aerosol processes during dry deposition, Aerosol Sci. Tech., 38, 1091-1098, doi:10.1080/027868290885827, 2004.

Pryor, S. C., Larsen, S. E., Sørensen, L. L., Barthelmie, R. J., Grönholm, T., Kulmala, M., Launiainen, S., Rannik, Ü., and Vesala, T.: Particle fluxes over forests: analyses of flux methods and functional dependencies, J. Geophys Res., 112, D07205, doi:10.1029/2006JD008066, 2007.

Pryor, S. C., Barthelmie, R. J., Sørense, L. L., Larsen, S. E., Sempreviva, A. M., Grönholm, T., Rannik, Ü., Kulmala, M., and Vesala, T.: Upward fluxes of particles over forests: when, where, why?, Tellus B, 60, 372-380, 2008.

Pryor, S. C., Barthelmie, R. J., and Hornsby, K. E.: Sizeresolved particle fluxes and vertical gradients over and in a sparse pine forest, Aerosol Sci. Tech., 47, 1248-1257, doi:10.1080/02786826.2013.831974, 2013.

Rannik, Ü., Aalto, P., Keronen, P., Vesala, T., and Kulmala, M.: Interpretation of aerosol particle fluxes over a pine forest: dry deposition and random errors, J. Geophys Res., 108, AAC 3.1AAC3.11, 2003.

Rannik, Ü., Mammarella, I., Aalto, P., Keronen, P., Vesala, T., and Kulmala, M.: Long-term particle flux observations Part I: Uncertainties and time-average statistics, Atmos. Environ., 43, 34313439, 2009a.

Rannik, Ü., Mammarella, I., Keronen, P., and Vesala, T.: Vertical advection and nocturnal deposition of ozone over a boreal pine forest, Atmos. Chem. Phys., 9, 2089-2095, doi:10.5194/acp-92089-2009, 2009b.

Rinne, J., Hakola, H., Laurila, T., and Rannik, Ü.: Canopy scale monoterpene emissions of Pinus sylvestris dominated forests, Atmos. Environ., 34, 1099-1107, 2000.

Rinne, J., Markkanen, T., Ruuskanen, T. M., Petäjä, T., Keronen, P., Tang, M.J., Crowley, J. N., Rannik, Ü., and Vesala, T.: Effect of chemical degradation on fluxes of reactive compounds - a study with a stochastic Lagrangian transport model, Atmos. Chem. Phys., 12, 4843-4854, doi:10.5194/acp-12-4843-2012, 2012.

Saunders, S. M., Jenkin, M. E., Derwent, R. G., and Pilling, M. J.: Protocol for the development of the Master Chemical Mechanism, MCM v3 (Part A): tropospheric degradation of nonaromatic volatile organic compounds, Atmos. Chem. Phys., 3, 161-180, doi:10.5194/acp-3-161-2003, 2003.

Smolander, S., He, Q., Mogensen, D., Zhou, L., Bäck, J., Ruuskanen, T., Noe, S., Guenther, A., Aaltonen, H., Kulmala, M., and Boy, M.: Comparing three vegetation monoterpene emission models to measured gas concentrations with a model of meteorology, air chemistry and chemical transport, Biogeosciences, 11, 5425-5443, doi:10.5194/bg-11-5425-2014, 2014.
Sogachev, A., Menzhulin, G., Heimann, M., and Lloyd, J.: A simple three dimensional canopy - planetary boundary layer simulation model for scalar concentrations and fluxes, Tellus B, 54, 784819, 2002.

Sogachev, A., Kelly, M., and Leclerc, M.: Consistent two-equation closure modelling for atmospheric research: buoyancy and vegetation implementations, Bound.-Lay. Meteorol., 145, 307-327, 2012.

Stull, R. B.: An Introduction to Boundary Layer Meteorology, Kluwer Academic Publishers, Dordrecht, the Netherlands, 1988.

Weber, R. J., Marti, J. J., McMurry, P. H., Eisele, F. L., Tanner, D. J., and Jefferson, A.: Measurements of new particle formation and ultrafine particle growth rates at a clean continental site, J. Geophys. Res.-Atmos., 102, 4375-4385, doi:10.1029/96JD03656, 1997.

Welz, O., Savee, J. D., Osborn, D. L., Vasu, S. S., Percival, C. J., Shallcross, D. E., and Taatjes, C. A.: Direct kinetic measurements of Criegee Intermediate $\left(\mathrm{CH}_{2} \mathrm{OO}\right)$ formed by reaction of $\mathrm{CH}_{2}$ I with $\mathrm{O}_{2}$, Science, 335, 204-207, 2012.

Whitehead, J. D., Gallagher, M. W., Dorsey, J. R., Robinson, N., Gabey, A. M., Coe, H., McFiggans, G., Flynn, M. J., Ryder, J., Nemitz, E., and Davies, F.: Aerosol fluxes and dynamics within and above a tropical rainforest in South-East Asia, Atmos. Chem. Phys., 10, 9369-9382, doi:10.5194/acp-10-9369-2010, 2010.

Wilson, J. D. and Sawford, B. L.: Review of Lagrangian stochastic models for trajectories in the turbulent atmosphere, Bound.-Lay. Meteorol., 78, 191-210, 1996.

Zelger, M., Schween, J., Reuder, J., Gori, T., Simmerl, K., and Dlugi, R.: Turbulent transport, characteristic length and time scales above and within the BEMA forest site at Castelporziano, Atmos. Environ., 31, 217-227, doi:10.1016/S13522310(97)00112-X, 1997.

Zhou, L., Nieminen, T., Mogensen, D., Smolander, S., Rusanen, A., Kulmala, M., and Boy, M.: SOSAA - a new model to simulate the concentrations of organic vapours, sulphuric acid and aerosols inside the ABL - Part 2: Aerosol dynamics and one case study at a boreal forest site, Boreal Environ. Res., 19, 237-256, 2014.

Zhou, L., Gierens, R., Sogachev, A., Mogensen, D., Ortega, J., Smith, J. N., Harley, P. C., Prenni, A. J., Levin, E. J. T., Turnipseed, A., Rusanen, A., Smolander, S., Guenther, A. B., Kulmala, M., Karl, T., and Boy, M.: Contribution from biogenic organic compounds to particle growth during the 2010 BEACHON-ROCS campaign in a Colorado temperate needleleaf forest, Atmos. Chem. Phys., 15, 8643-8656, doi:10.5194/acp15-8643-2015, 2015. 